\title{
Factors associated with induced abortion at selected hospitals in the Volta Region, Ghana
}

This article was published in the following Dove Press journal:

International Journal of Women's Health

2I August 2014

Number of times this article has been viewed

\author{
Ellen Eyi Klutsey' \\ Augustine Ankomah ${ }^{2}$ \\ 'School of Nursing and Midwifery, \\ University of Health and Allied \\ Sciences, Ho, Volta Region, \\ ${ }^{2}$ Department of Population, Family \\ and Reproductive Health School of \\ Public Health, University of Ghana, \\ Legon, Accra, Ghana
}

Correspondence: Augustine Ankomah Department of Population, Family and Reproductive Health School of Public Health, South Legon Road, Legon Campus, University of Ghana, Legon, Accra, Ghana

Email aankomah@ug.edu.gh
Background: Induced abortion rates remained persistently high in the Volta Region of Ghana in the 5 years from 2006 to 2011. Some hospitals, both rural and urban, report induced abortionrelated complications as one of the top ten conditions in hospital admissions. This study explored demographic and other factors associated with induced abortion, and also assessed awareness of abortion-related complications among women of reproductive age in the Volta Region.

Methods: A quantitative, hospital-based, unmatched case-control study was performed. The Volta Region was stratified into two health administration zones, ie, north and south. For each zone, hospitals were stratified into government and private hospitals. Employing simple random sampling, one private and three government hospitals were selected from each zone. This study is therefore based on eight hospitals, ie, six government hospitals and two private hospitals. Results: Marital status, employment status, number of total pregnancies, and knowledge about contraception were found to be associated with induced abortion. Multiple logistic regression showed a $4 \%$ reduction in the odds of induced abortion in married women compared with women who were single (odds ratio [OR] 0.11, 95\% confidence interval [CI] 0.07-0.22). Unemployed women of reproductive age were found to be 0.35 times less likely to seek induced abortion compared with their employed counterparts (OR 0.35, CI 0.19-0.65). It was also observed that women with their second pregnancies were 3.8 times more likely to seek induced abortion and women with more than two pregnancies were 6.6 times more likely to do so (OR 3.81, CI 1.94-7.49 and OR 6.58, CI 2.58-16.79, respectively). Women with no knowledge of contraceptive methods were 4.6 times likely to seek induced abortion (OR 4.64, CI 1.39-15.4). Compared with women who had not had induced abortion, women with a high number of pregnancies and no contraceptive knowledge were more likely to have induced abortion.

Conclusion: It was found that lack of knowledge about contraceptives and being single or employed were associated with increased likelihood of induced abortion. It was also found that women with a higher number of pregnancies have a greater odds of induced abortion. No association was found between induced abortion and maternal age, education, contraceptive use, or religion.

Keywords: induced abortion, case control, maternal mortality, hospital-based, Volta Region, Ghana

\section{Introduction}

Although abortion is practiced in most countries, with a worldwide rate of 29 per 1,000 women, there are substantial regional and subregional variations in its incidence and prevalence. ${ }^{1}$ The bulk of unsafe induced abortions occurs in the developing world. According to the World Health Organization, ${ }^{2}$ more than one third of the approximately 205 million pregnancies that occur worldwide annually are unintended. Of the estimated 182 million pregnancies that occur yearly in developing countries, more than one third 
are unintended, with $19 \%$ ending in induced abortion, $8 \%$ safely and $11 \%$ unsafely. $^{2}$ Worldwide, an estimated 5 million women of reproductive age are hospitalized annually for treatment of abortion-related complications, and Africa accounts for 1.7 million of this figure. Deaths from induced abortion are known to contribute to approximately $14 \%$ of all maternal deaths in Africa. ${ }^{1,2}$ It is also noted that almost all abortion-related deaths occur in developing countries, and Africa records the highest estimated mortality, ie, 650 deaths per 100,000 unsafe abortions. ${ }^{2}$

Abortion is a key proximate cause of maternal mortality in Ghana. ${ }^{3,4}$ Fifteen percent of all women in the reproductive age group (15-49 years) were found to have sought induced abortion, ${ }^{5}$ with induced abortion accounting for $11 \%$ of the maternal mortality rate of 350 deaths per 100,000 live births. The complications associated with illegal abortion have serious public health implications for Ghana because they increase maternal mortality and morbidity and divert limited health resources. ${ }^{5}$

Abortion rates in Ghana vary from site to site. A study in southern Ghana estimated 17 abortions per 1,000 women, ${ }^{6}$ Mote et $\mathrm{al}^{7}$ reported a rate of $21.3 \%$ from Hohoe in the Volta Region, while another study reported $22.6 \%$ in the Brong Ahafo Region. ${ }^{8}$

In terms of quinary age distribution, analysis of data from several countries around the world ${ }^{9,10}$ identified the age group of 20-24 years as the cohort with the highest proportion of abortions. However, studies in sub-Saharan Africa show that a fairly large number of women who terminate pregnancies are teenagers. ${ }^{11-14}$ This corresponds with the finding that adolescents comprise a substantial proportion of abortion seekers in many countries, and $59 \%$ of all abortions in Africa are estimated to occur in women aged younger than 25 years. ${ }^{11,12}$ In a hospital-based study in Nigeria, ${ }^{12} 60 \%$ of the sample $(n=1,876)$ was aged 14-24 years, with adolescents (15-19 years) accounting for $23 \%$. In Ghana, studies have confirmed youth as comprising the bulk of abortion patients. ${ }^{5,6,15,16}$ In contrast, a study in Hohoe municipality ${ }^{7}$ found that women aged 45-49 years were over five times more likely to undergo an abortion than those aged 15-24 years.

Abortion has also been found to be associated with marital status. Some studies report that never-marrieds are more likely to seek abortion. ${ }^{12,16-18}$ Others have found the highest proportion of abortion seekers among single ever-marrieds (divorced, separated, and widowed) compared with marrieds. ${ }^{5}$ Generally, women in urban areas are more likely to have an abortion than rural women. ${ }^{7}$ Studies in Ghana have reported that educated urban women are more likely to seek an abortion than their less educated rural counterparts. ${ }^{6}$ A study involving women admitted to hospital for post-abortion care found that only $17 \%$ had ever used contraception. ${ }^{19}$ Another study found that women in formal employment are more likely to seek abortion. ${ }^{5}$ In contrast, Oye-Adeniran et $\mathrm{al}^{12}$ found that the single highest group represented among abortion seekers comprised students while the others were predominantly traders.

The Volta Region, where the present study was done, contributed $18 \%$ of the national burden of induced abortions, being the third highest among the ten regions of Ghana. ${ }^{20}$ The number of recorded induced abortions increased from 676 in 2010 to 1,060 in 2011 in the Volta Region. ${ }^{20}$ Although induced abortion is a key health issue, very little is known about it in this region of Ghana, which is culturally different from other regions in the country. It is expected that data on factors associated with induced abortions will be important for advocacy and policies in the region for prevention of unwanted pregnancies and the betterment of maternal health. Thus, the findings of this study will help to outline specific priorities aimed at eliciting local evidence-based solutions geared towards prevention of unwanted pregnancies, and subsequently, induced abortion. The main objectives of this study were to identify factors associated with induced abortion in the Volta Region and to assess awareness of the potential complications associated with the procedure in the Volta Region.

\section{Materials and methods}

This was a quantitative, unmatched, hospital-based casecontrol study carried out in the Volta Region of Ghana from May to July 2012. Data were collected using an intervieweradministered close-ended questionnaire. The study population comprised two groups of women (cases and controls) of reproductive age who were seeking care at selected hospitals in the Volta Region, Ghana.

\section{Sampling}

The sample size was 380 , comprising 76 cases and 304 controls. Given that the study outcome, ie, abortion, is rare, it was both necessary and cost-effective to increase the numbers of controls. Since $80 \%$ of maximum efficiency can be obtained with four controls per case, it is generally unnecessary to seek a higher ratio. In general, the number of controls should be less than four, because there is no further gain of power above four controls per case. ${ }^{21}$ The region was stratified into two health administration zones, ie, north and south. For each zone, hospitals were stratified into government and private hospitals. Using simple random sampling, 
one private and three government hospitals were selected from each zone. Therefore, the study included eight hospitals (six government and two private).

\section{Cases}

Cases were women of reproductive age seeking health care at the selected hospitals for induced abortion or its complications or receiving antenatal care but who had had induced abortion in the previous 5 years. We excluded women who were receiving treatment for complications of induced abortion but were too ill to talk or were younger than 15 years of age. Based on medical records, women of reproductive age who had had induced abortion, had been hospitalized, or reported abortion-related complications on review in the selected hospitals were recruited as cases if they consented to participate in the study. Cases were selected from the medical records of pregnant women to identify those who had a history of induced abortions. Also included as cases were women who, during the study period, reported at the facilities with abortion-related problems.

\section{Controls}

The controls were selected from antenatal and postnatal clinics (up to 6 weeks after delivery), and comprised pregnant or lactating women seeking prenatal or postnatal care at the respective hospitals but who had never had an induced abortion. We excluded pregnant women who reported a history of induced abortion, pregnant women who were too ill to talk, and those who were younger than 15 years of age.

\section{Data collection}

Modified structured questionnaires were administered during face-to-face interviews after a pretest. Two registered general nurses with prior field research experience were recruited from each selected hospital and trained as interviewers.

\section{Data processing and analysis}

Double entry was performed during data processing for consistency. Using Stata MP version 11.0 software (StataCorp LP, College Station, TX, USA), Pearson's chi-squared test was used to investigate the association between induced abortion and each of the independent variables, and thus the bivariate analysis. Logistic regression was used to investigate the effect of each of these variables on the odds of induced abortion. Variables that emerged with a $P$-value of 0.05 or less were included in the logistic regression model.

\section{Ethical considerations}

Approval for the study was obtained from the ethics review committee of the Ghana Health Service. Further approval was also granted from the Volta Regional Health Directorate as well as the gatekeepers at the various hospitals selected for the study and larger communities where necessary. Confidentiality was maintained and informed consent was obtained from all participants before the questionnaires were administered.

\section{Results \\ Sociodemographic characteristics of respondents}

The sociodemographic characteristics of the respondents are presented in Table 1. The mean age of respondents overall was $23.6 \pm 4.8$ years, the mean age of the cases was $22.6 \pm 5.1$ years, and the mean age of the controls was $23.8 \pm 4.8$ years. The majority of respondents in both subpopulations had at least primary level education. Among the cases, only $7.9 \%$ did not have any formal education compared with $16 \%$ of the controls. More than half of each subpopulation (cases $56.2 \%$, controls $59.2 \%$ ) had at least primary education and at most a

Table I Sociodemographic characteristics of cases and controls of induced abortion in the Volta Region

\begin{tabular}{|c|c|c|}
\hline \multirow[t]{2}{*}{ Characteristic } & \multicolumn{2}{|l|}{ Frequency (\%) } \\
\hline & Cases $(n=76)$ & Controls $(n=304)$ \\
\hline \multicolumn{3}{|l|}{ Age, years } \\
\hline$<20$ & $23(30.3)$ & $54(17.8)$ \\
\hline $20-29$ & $46(60.5)$ & $214(70.3)$ \\
\hline $30+$ & $7(9.2)$ & $36(11.9)$ \\
\hline \multicolumn{3}{|l|}{ Marital status } \\
\hline Single* & $58(76.3)$ & 97 (3I.I) \\
\hline Married & $18(23.7)$ & $207(68.1)$ \\
\hline \multicolumn{3}{|l|}{ Ethnicity } \\
\hline Ewe & $59(77.6)$ & $226(74.3)$ \\
\hline Others & $17(22.4)$ & $78(26.7)$ \\
\hline \multicolumn{3}{|l|}{ Religion } \\
\hline Christian & $68(89.5)$ & 240 (78.9) \\
\hline Non-Christian & $8(10.5)$ & $64(21.1)$ \\
\hline \multicolumn{3}{|l|}{ Educational level } \\
\hline No formal education & $6(7.9)$ & $47(15.5)$ \\
\hline Primary education & $8(10.5)$ & $59(19.4)$ \\
\hline JSS/middle school education & 37 (48.7) & $112(36.8)$ \\
\hline Secondary and above & $25(32.9)$ & $86(28.3)$ \\
\hline \multicolumn{3}{|l|}{ Occupation } \\
\hline Unemployed & $46(60.5)$ & $96(31.6)$ \\
\hline Employed & $30(39.5)$ & $208(68.4)$ \\
\hline \multicolumn{3}{|l|}{ Residence } \\
\hline Urban & $65(85.5)$ & $236(77.6)$ \\
\hline Rural & II (I4.5) & $68(22.4)$ \\
\hline
\end{tabular}

Note: *Singles include never married and divorced women. Abbreviation: JSS, junior high school. 
middle school/junior high school education. Over one third of cases (39.5\%) were employed, while more than two-thirds $(68.4 \%)$ of the controls were employed. Both cases and controls were predominantly of the Ewe ethnic group (cases $77.6 \%$, controls 74.3\%) and were Christian (cases 89.5\%, controls $78.9 \%$ ).

More than two thirds $(71.1 \%)$ of the cases were aged 15-24 years, and $30.3 \%$ were in their late teens. Likewise, more than half $(59.3 \%)$ of the control subjects were 24 years or younger. Induced abortion peaked among women in their twenties and tapered off in the teens and women in their thirties. However, there was no statistically significant difference in age with regard to induced abortion. In terms of marital status, the two groups were significantly different. As shown in Table 2, more than three quarters $(76.3 \%)$ of the cases were single compared with only $31 \%$ of the controls $(P<0.0001)$. There was a significantly higher proportion of Christians among the cases (89.5\%) compared with controls $(78.9 \%)$. Cases were also more likely to be Christian $(P=0.040)$.

Table 2 Potential risk factors in cases and controls for seeking induced abortion in the Volta Region

\begin{tabular}{|c|c|c|c|}
\hline \multirow[t]{2}{*}{ Characteristic } & \multicolumn{2}{|l|}{ Frequency (\%) } & \multirow{2}{*}{$\begin{array}{l}\text { Pearson chi-square } \\
P \text {-value }\end{array}$} \\
\hline & Cases $(n=76)$ & Controls $(n=304)$ & \\
\hline \multicolumn{4}{|l|}{ Age, years } \\
\hline$<20$ & $23(30.3)$ & $54(17.8)$ & 0.057 \\
\hline $20-29$ & $46(60.5)$ & $2 \mid 4(70.3)$ & \\
\hline $30+$ & $7(9.2)$ & $36(11.9)$ & \\
\hline \multicolumn{4}{|l|}{ Marital status } \\
\hline Single & $58(76.3)$ & 97 (3I.I) & $<0.0001$ \\
\hline Married & $18(23.7)$ & $207(68.1)$ & \\
\hline \multicolumn{4}{|l|}{ Ethnicity } \\
\hline Ewe & $59(77.6)$ & $226(74.3)$ & 0.449 \\
\hline Other & $17(22.4)$ & $78(26.7)$ & \\
\hline \multicolumn{4}{|l|}{ Religion } \\
\hline Christian & $68(89.5)$ & 240 (78.9) & 0.040 \\
\hline Other & $8(10.5)$ & $64(21.1)$ & \\
\hline \multicolumn{4}{|l|}{ Employment status } \\
\hline Employed & $30(39.5)$ & $208(68.4)$ & $<0.0001$ \\
\hline Unemployed & $46(60.5)$ & $96(31.6)$ & \\
\hline \multicolumn{4}{|l|}{ Educational level } \\
\hline No formal education & $6(7.9)$ & $47(15.5)$ & 0.050 \\
\hline Primary & $8(10.5)$ & $59(19.4)$ & \\
\hline JSS/middle school & $37(48.7)$ & $112(36.8)$ & \\
\hline Senior secondary or above & $25(32.9)$ & $86(28.3)$ & \\
\hline \multicolumn{4}{|l|}{ Area of residence } \\
\hline Urban & $65(85.5)$ & $236(77.6)$ & 0.130 \\
\hline Rural & II (I4.5) & $68(22.4)$ & \\
\hline \multicolumn{4}{|l|}{ Number of pregnancies } \\
\hline One & $30(39.5)$ & $154(50.7)$ & $<0.0001$ \\
\hline Two & $33(43.4)$ & $100(32.9)$ & \\
\hline Three & $13(17.1)$ & $50(16.4)$ & \\
\hline \multicolumn{4}{|l|}{ Number of children living } \\
\hline None & $65(85.5)$ & $260(85.5)$ & 1.000 \\
\hline One & $7(9.2)$ & $28(9.2)$ & \\
\hline Two or more & $4(5.3)$ & $16(5.3)$ & \\
\hline \multicolumn{4}{|l|}{ Contraceptive knowledge } \\
\hline Knows at least one FP method & $67(88.2)$ & $290(95.4)$ & 0.006 \\
\hline Knows no FP method & $9(11.8)$ & $14(4.6)$ & \\
\hline \multicolumn{4}{|l|}{ Contraceptive use } \\
\hline FP prior to current pregnancy & $42(55.3)$ & $164(53.9)$ & 0.840 \\
\hline Non FP prior to pregnancy & $34(44.7)$ & $140(46.1)$ & \\
\hline \multicolumn{4}{|l|}{ Awareness of complications } \\
\hline Aware of at least one complication & $67(88.2)$ & $279(91.8)$ & 0.977 \\
\hline Unaware of complications & $9(I I .8)$ & $25(8.2)$ & \\
\hline
\end{tabular}

Abbreviations: JSS, junior high school; FP, family planning. 
Both cases and controls were predominantly Ewes (cases $77.6 \%$, controls $74.3 \%$ ) and from the urban community (cases $85.5 \%$, controls $77.6 \%$ ). Table 2 shows that ethnicity and area of residence were not significant factors influencing the likelihood of seeking induced abortion ( $P=0.449$ and $P=0.130$, respectively). Employment status was a statistically significant factor in relation to induced abortion $(P<0.0001)$. At the bivariate level, those who were employed were more likely to have had induced abortion.

In terms of education, only $7.9 \%$ of the cases did not have any formal education, but the rest had at least primary level education. Sixteen percent of the controls also had no formal education. Thus, $92.1 \%$ of cases and $84.5 \%$ of controls had at least primary level education. Among both the case and control groups, most subjects had junior high school or middle school education as their highest level of formal education (cases $48.7 \%$, controls $36.8 \%$ ). Table 2 shows a significant association between education and induced abortion, with more educated women having a higher likelihood of induced abortion.

The number of pregnancies is significant in relation to induced abortion $(P<0.0001)$ but not parity $(P=1.00)$ (Table 2).

Most of the respondents $(88.2 \%$ of cases and $95.4 \%$ of controls) knew of at least one method of contraception; however, fewer cases $(55.5 \%)$ and controls (53.9\%) were using a contraceptive method prior to their recent pregnancy. Although there was strong evidence of an association between contraceptive knowledge and induced abortion $(P=0.006)$, there was no evidence of an association between contraceptive use and induced abortion $(P=0.840$, Table 2).

With regard to abortion complications, $88.2 \%$ of cases knew of at least one complication of induced abortion compared with $91.8 \%$ of controls. The most common postabortion complication reported by the women was death $(82 \%)$, followed by infertility (58\%), whereas the least known complication reported by the women was foul smelling discharge (2.6\%, data not shown). Statistically, there was no association between induced abortion and awareness of the complications of induced abortion.

\section{Logistic regression}

Multiple logistic regression was used to assess the possible association between the independent variables and abortion while controlling for other factors. Marital status, employment status, and total number of pregnancies were found to be associated with induced abortion. After adjusting for the effects of employment status and total number of pregnancies, there was a $4 \%$ reduction in the odds of induced abortion among married women compared with women who were single (odds ratio [OR] 0.11, confidence interval $[\mathrm{CI}] 0.07-0.22 ; P<0.0001)$. Similarly, after adjusting for the combined effects of marital status and number of total pregnancies, those who were unemployed were 0.35 times less likely to have induced abortion compared with those who were employed (OR 0.35, CI 0.19-0.65; $P<0.001)$.

Adjusting for the combined effects of employment status and marital status, there was evidence that women with their second pregnancies were 3.8 times more likely to seek induced abortion, while women with more than two pregnancies were 6.6 times more likely to do so. The increase in the odds of induced abortion with regard to increase in number of total pregnancies, suggests a doseresponse relationship; thus, the higher the number of total pregnancies, the higher the odds of induced abortion $(P<0.0001$, Table 3$)$. When marital status and employment status as well as religion were accounted for jointly, women who had no knowledge of contraceptive methods were 4.6 times at risk of induced abortion. Although there was an association between induced abortion and each of age, religion, and educational level in bivariate analysis (Table 2 ), no statistically significant associations were found at the multivariate level (Table 3). The lack of association between religion and abortion supports the findings of Schwandt et al ${ }^{16}$.

\section{Discussion}

This case-control study was carried out in selected hospitals in the Volta Region to determine factors associated with induced abortion. Marital status, employment status, number of total pregnancies, and contraceptive knowledge were found to have a strong association with induced abortion. Although there was an association between induced abortion and each of age, religion, and educational level in bivariate analysis, these associations were not statistically significant at the multivariate level.

The study showed strong evidence of a reduction in the odds of induced abortion among married women compared with women who had never married or were divorced. More than three quarters of the women who sought induced abortion were unmarried. This is similar to findings from other studies in Ghana ${ }^{16,17}$ reporting that abortion seekers were likely to be unmarried (never marrieds, divorced, or separated). However, our findings are in contrast with those of another study in Ghana which found that women who 
Table 3 Crude and adjusted odds ratios of risk factors for seeking induced abortion among women of reproductive age (I 5-45 years) in the Volta Region

\begin{tabular}{|c|c|c|c|}
\hline Potential risk factors & $\begin{array}{l}\text { Crude OR } \\
(95 \% \mathrm{Cl})\end{array}$ & $\begin{array}{l}\text { Adjusted OR } \\
(95 \% \mathrm{Cl})\end{array}$ & $P$-value \\
\hline \multicolumn{4}{|l|}{ Marital status } \\
\hline \multicolumn{4}{|l|}{ Single (ref) } \\
\hline Married & $0.11(0.07-0.22)$ & $0.15(0.08-0.26)$ & $<0.0001$ \\
\hline \multicolumn{4}{|l|}{ Number of pregnancies } \\
\hline \multicolumn{4}{|l|}{ First pregnancy (ref) } \\
\hline Second pregnancy & $1.69(0.97-2.95)$ & $3.81(1.94-7.49)$ & $<0.000$ I \\
\hline Third of more pregnancies & $1.33(0.65-2.76)$ & $6.58(2.58-16.79)$ & \\
\hline \multicolumn{4}{|l|}{ Occupation } \\
\hline \multicolumn{4}{|l|}{ Employed (ref) } \\
\hline Unemployed & $0.30(0.18-0.5 I)$ & $0.35(0.19-0.65)$ & $<0.01$ \\
\hline \multicolumn{4}{|c|}{ Contraceptive knowledge } \\
\hline \multicolumn{4}{|c|}{ Knows at least one FP method (ref) } \\
\hline Knows no FP method & $0.58(0.29-1.17)$ & $4.64(1.39-15.4)$ & 0.01 \\
\hline \multicolumn{4}{|l|}{ Religion } \\
\hline \multicolumn{4}{|l|}{ Christian (ref) } \\
\hline Non-Christian & $0.44(0.20-0.97)$ & $0.75(0.3-1.62)$ & 0.59 \\
\hline \multicolumn{4}{|l|}{ Educational level } \\
\hline \multicolumn{4}{|l|}{ No formal education (ref) } \\
\hline Primary education & $1.06(0.34-3.27)$ & $1.09(0.33-3.58)$ & 0.59 \\
\hline JSS/middle school education & $2.59(1.02-6.54)$ & $1.86(0.67-5.15)$ & \\
\hline Secondary and above & $2.28(0.87-5.94)$ & $2.19(0.75-6.35)$ & \\
\hline \multicolumn{4}{|l|}{ Age, years } \\
\hline \multicolumn{4}{|l|}{$15-19$ (ref) } \\
\hline $20-24$ & $0.58(0.3 \mathrm{I}-1.08)$ & $1.21(0.22-6.59)$ & 0.83 \\
\hline $25-29$ & $0.40(0.19-0.83)$ & $1.18(0.25-5.48)$ & \\
\hline$\geq 30$ & $0.46(0.18-1.17)$ & $1.16(0.27-5.28)$ & \\
\hline \multicolumn{4}{|l|}{ Residence } \\
\hline \multicolumn{4}{|l|}{ Urban (ref) } \\
\hline Rural & $0.59(0.29-1.18)$ & $0.52(0.24-1.14)$ & 0.10 \\
\hline
\end{tabular}

Abbreviations: $\mathrm{Cl}$, confidence interval; FP, family planning; JSS, junior high school; OR, odds ratio; ref, reference.

sought induced abortion were more likely to be married. ${ }^{6}$ The findings of this study reflect the tradition in the Volta Region of society frowning on premarital sex as well as childbearing outside wedlock. The stigma associated with pregnancy outside wedlock could explain the higher rate of induced abortion among single women.

Employment status is another factor strongly associated with induced abortion. Women who were unemployed were less likely to seek induced abortion than those who were employed. This finding confirms other studies in Ghana ${ }^{7}$ and Nigeria, ${ }^{12}$ and supports the observation that employed women are more likely to seek induced abortion than their counterparts who are not working. ${ }^{9}$ Calves $^{22}$ also noted that women in Cameroon who sought induced abortion were more likely than others to be employed.

Increasing parity was also observed to be strongly associated with induced abortion. Compared with women with a single pregnancy, women with a second pregnancy were 3.8 times more likely to seek induced abortion, and women with more than two previous pregnancies were 6.6 times at risk. This observation supports the view that in adopting the ideals of small family size in developing countries, the number of unintended pregnancies will increase, and in turn increase the likelihood of women seeking induced abortion. $^{23}$

Women who had no knowledge of contraceptive methods were at greater risk (OR 4.7) of inducing abortion compared with those who knew of at least one method of contraception. This finding is consistent with other studies showing that rates of termination of pregnancy tend to decline with increased knowledge about contraception. ${ }^{2,18}$ This may stem from the fact that women with no knowledge of contraception are unable to protect themselves against unintended pregnancies and so seek abortion to avoid having unwanted children.

Our finding that women who seek induced abortion are more likely to report no religious affiliation confirms the report of Schwandt et al. ${ }^{16}$ However, unlike other studies, ${ }^{2,6,16}$ we did 
not find any association between induced abortion and age, education, or contraceptive use. The absence of an association between formal education and induced abortion may be due to the use of induced abortion as a means of ending unintended pregnancies by both educated and noneducated women. Regarding contraceptive use, it could be that women who had induced abortion started using contraceptives after the abortion, hence the absence of an association between induced abortion and contraceptive use. A recent study in Ghana appears to support this by noting that a number of respondents who had their first abortion earlier had since gained knowledge of contraceptives and were using them. ${ }^{24}$ It must be noted that this study did not obtain information on the timing of contraception.

Inefficient use of contraception among users with resulting induced abortion for unintended pregnancy may also account for the absence of an association in this study. In the same vein, it could be that when faced with the burden of unintended pregnancy, a female rural or urban dweller with or without children would resort to induced abortion regardless of her faith, explaining the lack of an association between area of residence, parity, and religion in this study.

\section{Limitations}

The study is hospital-based, so the population sample may not be representative of the situation at the community level. There could be some misclassification, since the status of abortion for controls was self-reported. It is likely that induced abortion was misclassified as spontaneous abortion and vice versa in some cases. This study was also susceptible to recall bias, as its participants may not have been able to accurately remember issues from the past.

\section{Conclusion}

This study found that marital status is associated with induced abortion. Married women are less likely to seek induced abortion than their single counterparts. It was also found that unemployed women were less likely to seek induced abortion than women who were employed. Lack of knowledge about contraception was also found to increase the likelihood of induced abortion. It was also found that women with a higher number of pregnancies have higher odds of induced abortion. No association was found between induced abortion and age, education, or contraceptive use. It could be that when faced with the burden of unintended pregnancy, both rural and urban dwellers with or without children would resort to induced abortion regardless of their faith, explaining the lack of an association between area of residence, parity, or religion in this study. There is a need for regular integrated community-based outreach programs aimed at creating community awareness of effective contraception and avoidance of unintended pregnancy. There is also a need for qualitative research to understand better the key risk factors for induced abortion to help plan specific interventions aimed at eliminating abortion-related health risks.

\section{Disclosure}

The authors report no conflicts of interest in this work.

\section{References}

1. Allan Guttmacher Institute. Facts on Abortion in Africa. Available from: http://www.guttmacher.org/pubs/IB_AWW-Africa.pdf. Accessed June 18, 2014.

2. World Health Organization. Unsafe Abortion: Global and Regional Estimates of the Incidence and Mortality in 2008. 6th ed. Geneva, Switzerland: Department of Reproductive Health and Research, World Health Organization; 2011. Available from: http://www.who.int/ reproductivehealth/publications/unsafe_abortion. Accessed June 18, 2014.

3. Mills S, Williams JE, Wak G, Hodgson A. Maternal mortality decline in the Kassena-Nankana district of Northern Ghana. Matern Child Health J. 2008;12:577-585.

4. Zakariah AY, Alexander S, van Roosmalen J, Buekens P, Kwawukume EY, Frimpong P. Reproductive age mortality survey (RAMOS) in Accra, Ghana. Reprod Health. 2009;6:1-6.

5. Ghana Statistical Service, Ghana Health Service, Macro International. Ghana maternal health survey. Available from: http://pdf.usaid.gov/ pdf_docs/PNADO492.pdf. Accessed June 19, 2014.

6. Ahiadeke C. Incidence of induced abortion in Southern Ghana. Int Fam Plan Perspect. 2001;27:96-101.

7. Mote C, Otupiri E, Hindin M. Factors associated with induced abortion among women in Hohoe, Ghana. Afr J Reprod Health. 2010;14: $115-121$.

8. Geelhoed DW, Nayembil D, Asare K, Schagen van Leewen JH, van Roomsmalen J. Contraception and induced abortion in rural Ghana. Trop Med Int Health. 2002; 7:708-716.

9. Bankole A, Singh S, Haas T. Characteristics of women seeking abortion: a worldwide review. Int Fam Plan Perspect. 1999;25:68-77.

10. Murray N, Winfrey W, Chateryi M, Moreland S, Dougherthy L, Okonofua F. Factors related to induced abortion among young women in Edo State, Nigeria. Stud Fam Plann. 2006;37:251-268.

11. Adanu RMK, Ntumy MN, Tweneboah E. Profile of women with abortion complications in Ghana. Trop Doct. 2005;35:139-142.

12. Oye-Adeniran BA, Adewole IF, Umoh AV, Fapohunda OR, Iwere N. Characteristics of abortion seekers in Southwestern Nigeria. Afr $J$ Reprod Health. 2004;8:81-91.

13. Ibrahim IA, Onwudiegwu U. Socio-demographic determinants of complicated unsafe abortions in a semi-urban Nigerian town: a four-year review. West Indian Med J. 2012;61:163-167.

14. Aderibigbe SA, Araoye MO, Akande TM, Musa OI, Monehin JO, Babatunde OA. Teenage pregnancy and prevalence of abortion among in-school adolescents in North Central, Nigeria. Asian Social Science. 2011;7:122-127.

15. Yeboah RWN, Kom MC. Abortion: the case of Chinard ward, Korle-Bu from 2000 to 2001. The Research Review of the Institute of African Studies. 2003;19:57-66.

16. Schwandt HM, Creaga AA, Danso KA, Adanu RMK, Agbenyega T, Hindin MJ. A comparison of women with induced abortion, spontaneous abortion and ectopic pregnancy in Ghana. Contraception. 2011;84(1):87-93. 
17. Oliveras E, Ahiadeke C, Adanu RM, Hill AG. Clinic based surveillance of adverse pregnancy outcomes to identify induced abortions in Accra, Ghana. Stud Fam Plann. 2008;29:133-140.

18. Mpangile GS, Leshabari MT, Kihwele DJ. Induced abortion in Dar es Salaam, Tanzania: the plight of adolescents. In: AI Mundigo AI, Indriso C, editors. Abortion in the Developing World. New Delhi, India: World Health Organization; 1999.

19. Aniteye P, Mayhew S. Attitudes and experiences of women admitted to hospital with abortion complications in Ghana. Afr J Reprod Health. 2011;15:47-55.

20. Ghana Health Service, Volta Regional Health Management Team. 2008 Annual Report. Ho, Ghana, 2009. Available from: http:// www.ghanahealthservice.org/documents/2011\%20ANNUAL\%20 REPORT\%20FINAL.pdf. Accessed June 23, 2014.
21. Breslow NE. Case-control studies. In: Ahrens W, Pigeot I, editors. Handbook of Epidemiology. Berlin, Germany: Springer; 2005.

22. Calves A. Abortion risk and decision making among young people of Cameroon. Stud Fam Plann. 2002;33:249-60.

23. Mundigo IA. Determinants of unsafe induced abortion in developing countries. In: Warriner IK, Shah IH, editors. Preventing Unsafe Abortion and Its Consequences: Priorities For Research and Action. New York, NY, USA: Guttmacher Institute; 2006.

24. Biney AAE. Exploring contraceptive knowledge and use among women experiencing induced abortion in the Greater Accra Region, Ghana. Afr J Reprod Health. 2011;15:37-46.

\section{Publish your work in this journal}

The International Journal of Women's Health is an international, peerreviewed open-access journal publishing original research, reports, editorials, reviews and commentaries on all aspects of women's healthcare including gynecology, obstetrics, and breast cancer. The manuscript management system is completely online and includes a very quick and fair peer-review system, which is all easy to use. Visit http://www.dovepress.com/testimonials.php to read real quotes from published authors.

Submit your manuscript here: http://www.dovepress.com/international-journal-of-womens-health-journal 